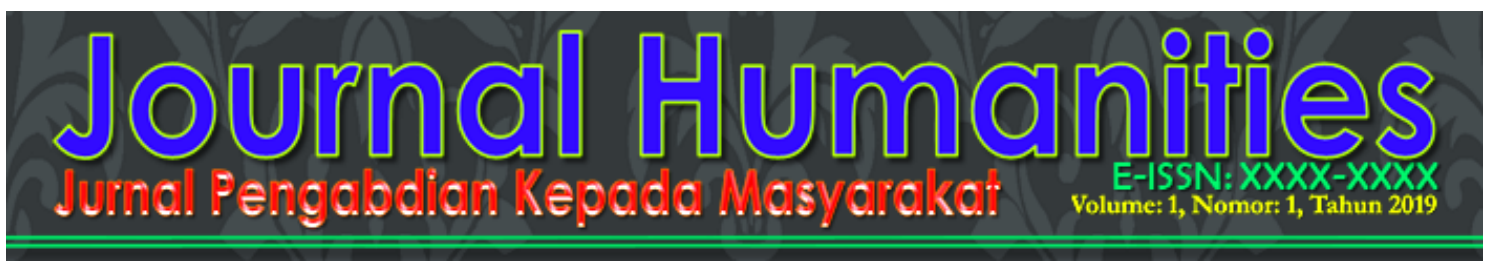

\title{
Implementation of Learning and Fundamental Measurement of Early Childhood Motor Skill for PAUD Teachers Padang Panjang City
}

\author{
Syahrial Bakhtiar ${ }^{1}$, Zainul Johor ${ }^{2}$, Oktarifaldi ${ }^{3}$, Lucy Pratama Putri ${ }^{4}$ \\ ${ }^{1234}$ Program Studi Pendidikan Jasmani Kesehatan dan Rekreasi, Fakultas Ilmu Keolahragaan, \\ Universitas Negeri Padang. Jalan Prof. Dr. Hamka Air Tawar Barat, Padang, 25132, Indonesia. \\ Email: $\frac{\text { syahrial@fik.inp.ac.id } 1}{\text { lucy_pratama@ } \underline{\text { zainul195.unp.ac.id }}{ }^{4}}$
}

\section{Abstract}

Research shows that physical activity of children at an early age will greatly trigger the development of cognitive abilities. Based on observations and studies in the field, it was found that almost all teachers and educators in PAUD Padang Panjang did not have the skills in designing learning and evaluating the basic movements of children. Based on research, basic motion cannot develop naturally but must be taught correctly and continuously. The learning material to be realized must be based on the child's initial ability and level of movement skills. This community service activity for partners aims to: (a) possess skills in designing fundamental motor skills learning, (b) understand and be skilled in using early childhood fundamental motor skill measurement instruments, (c) able to effectively implement learning in school places respective agencies. The method used uses the principle that every innovation received by PAUD teachers through PIE (Preparation, Implementation and Evaluation). This means that the delivery of innovations to Partners is carried out through the stages of explanation, discussion, practice as well as the evaluation phase with assistance in the learning process. Based on the implementation of the training, the results obtained for PAUD teachers in Padang Panjang as training participants can be described as follows: (a) has the skills in designing fundamental motor skill learning, (b) understanding and skilled in using fundamental motor skills measurement instruments for early childhood, (c) able to effectively implement learning in their respective school offices.

Keywords: Motor Skill Fundamentals, TGMD Instruments, PAUD Teachers

\section{Implementasi Pembelajaran dan Pengukuran Fundamental Motor Skill Anak Usia Dini Bagi Guru PAUD Kota Padang Panjang}

\begin{abstract}
Abstrak
Riset membuktikan bahwa aktifitas fisik anak pada usia dini akan sangat memicu perkembangan kemampuan kognitif. Berdasarkan observasi dan studi di lapangan, ditemui hampir seluruh guru dan tenaga pendidik di PAUD kota Padang Panjang belum memiliki keterampilan dalam merancang pembelajaran dan mengevaluasi gerak dasar anak. Berdasarkan penelitian, gerak dasar tidak dapat berkembang dengan alami melainkan harus diajarkan secara benar dan kontiniu. Materi pembelajaran yang akan direalisasikan harus berdasarkan kemampuan awal dan level keterampilan gerak anak. Kegiatan pengabdian kepada masyarakat ini bagi mitra bertujuan untuk : (a) memiliki keterampilan dalam merancang pembelajaran fundamental motor skill, (b) paham dan terampil dalam menggunakan instrument pengukuran fundamental motor skill anak usia dini, (c) mampu mengimlementasikan
\end{abstract}

36 | Implementation Of Learning And Fundamental Measurement Of Early

Syahrial Bakhtiar ${ }^{1}$, Zainul Johor ${ }^{2}$, Oktarifaldi ${ }^{3}$, Lucy Pratama Putri ${ }^{4}$

http://jha.ppj.unp.ac.id 


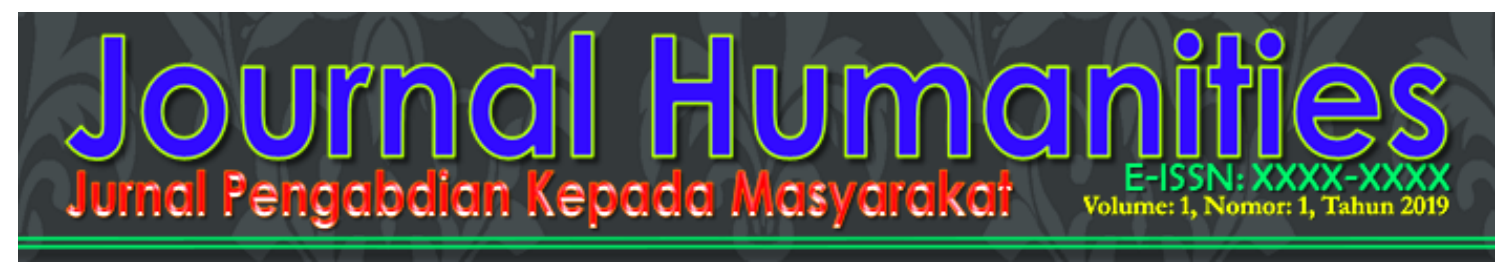

pembelajaran secara efektif di sekolah tempat dinas masing-masing. Metode yang dilakukan menggunakan prinsip bahwa setiap inovasi yang diterima oleh guru PAUD melalui PIE (Preparation, Implementation and Evaluation). Hal ini berarti penyampaian inovasi kepada Mitra ditempuh melalui tahapan penjelasan, diskusi, praktek serta dilakukan tahapan evaluasi dengan pendampingan dalam proses pembelajaran. Berdasarkan pelaksanaan pelatihan diperoleh hasil bagi guru PAUD kota Padang Panjang sebagai peserta pelatihan yang dapat dideskripsikan hal sebagai berikut: (a) memiliki keterampilan dalam merancang pembelajaran fundamental motor skill, (b) paham dan terampil dalam menggunakan instrument pengukuran fundamental motor skill anak usia dini, (c) mampu mengimlementasikan pembelajaran secara efektif di sekolah tempat dinas masing-masing.

Kata Kunci: Fundamental Motor Skill, Instrumen TGMD, Guru PAUD

\section{ANALISIS SITUASI}

Upaya yang dapat dilakukan oleh Negara untuk menghadapi tantangan global salah satunya dengan menyiapkan Sumber Daya Manusia (SDM) yang handal. Sumber daya handal yang dimaksud tidak dapat bergitu saja tercipta dalam waktu singkat, salahsatu upaya adalah memberikan perhatian terhadap pendidikan anak usia dini. Pendidikan anak usia dini (PAUD) adalah suatu upaya pembinaan yang ditujukan kepada anak sejak lahir sampai usia enam tahun yang dilakukan melalui pemberian rangsangan untuk membantu pertumbuhan dan perkembangan jasmani dan rohani agar anak memiliki kesiapan dalam memasuki pendidikan lebih lanjut (UURI N0. 20/2003

Bab I Ps. 1 btr 14). Diharapkan penanganan dalam pendidikan anak usia dini harus benar-benar dilakukan dengan serius berdasarkan undang-undang dan peraturan pemerintah secara syah. Hasil laporan yang diterbitkan olehl UNESCO bahwa PAUD yang berkembang di Indonesia ternyata lebih mementingkan pengajaran terhadap domain kognitif anak seperti, menulis, membaca dan berhitung. Sementara untuk domain psikomotor sangat jarang diajarkan oleh guruguru yang mengajar pada jenjang ini. Tentu saja ini menyalahi teori perkembangan kognitif yang dicetuskan oleh Piaget bahwa perkembangan kognitif anak-anak pada usia dini sangat dipengaruhi oleh perkembangan motoric mereka, demikian pula sebaliknya (Piaget dalam Dahar, 2006). Teori ini menjelaskan mekanissme seorang anak melakukan adaptasi dengan lingkungan sekitar melalui penginterpretasian objek serta kejadian.

Studi terdahulu menggambarkan bahwa pelaksanaan PAUD belum merealisasikan dan memenuhi standar sesuai dengan Permendiknas No.58 tahun 2009. Oleh sebab itu tidaklah heran apabila kemampuan motorik anak pada jenjang pendidikan ini belum tercapai dikarenakan guru-guru lebih focus mengasah kemampuan akademik anak saja padahal keterampilan gerak dasar bagi anak juga harus dikembangkan pada usia ini. Pada usia 3 sampai 10 tahun meruapkan usia emas pertumbuhan dan perkembangan kemampuan objek control dan lokomotor ( $\mathrm{Li}, 2009)$.

Pemahaman yang kurang dari guru-guru PAUD terhadap perkembangan gerak dasar serta metode pembelajaran yang diberikan besar pengaruhnya terhadap ketidaktercapaian indikator perkembangan motorik anak.Keterampilan gerak dasar adalah kemampuan gerak dasar yang harus dimiliki oleh setiap anak untuk menunjang aktivitas fisik dan keterlibatanya dalam aktivitas olahraga (Clark, Metcalfe, 2002, Lubans, Morgan, Cliff, Barnet, Okely, 2010).

Anak dengan keterampilan gerak dasar yang lemah mempunyai kecenderungan susah beradaptasi dengan teman-teman sebayanya karena timbul rasa rendah diri ketika 


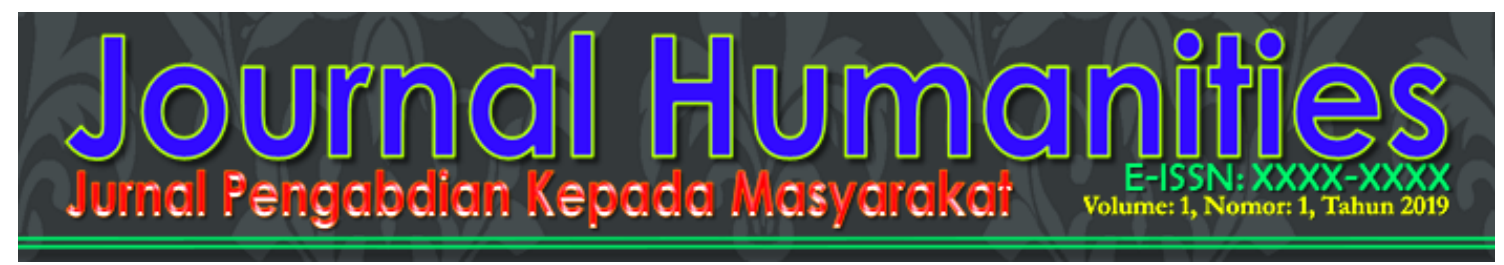

teman-temanya melakukan aktivitas fisik dan anak tidak mampu untuk mencotoh (Ulrich, 2000). Selain itu keaktivan anak dalam bergerak dapat mendatangkan dampak positif bagi kesehatan mereka, sirkulasi darah dan pernafasan menjadi lebih lancer juga dapat menunjang pertumbuhan fisik.Keterampilan gerak dasar anak terbagi kedalam kemampuan lokomotor (berjalan, berlai, melompat, lari senang dan lari kuda), kemdian ada kemampuan manipulative (menangkap, melempar dan menendang) terakhir kemampuan keseimbangan (merubah dan menggerakan tubuh dari satu tempat ke tempat lain, berdiri satu kaki, berjalan jinjit, dll) (Stodden et al., 2008; Jakub, Martin \& Petr, 2017).

Beberapa waktu lalu pengabdi telah melakukan kegiatan pelatihan bagi guru- guru PAUD dalam rangka meningkatkan pengetahuan dan wawasan mereka terhadap bagaimana cara efektif dalam memberikan materi pembelajaran gerak dasar pada siswa PAUD. Hal ini didasarkan pada temuan-temuan dilapangan serta hasil peneliti sebelumnya yang menyatakan bahwa kompetensi dan keterampilan mengajar guru anak usia dini masih rendah (Yusria, 2012, Balai Pendidikan dan Pemberdayaan Manusia dan Kebudayaan) dan juga kurangnya pengetahuan mereka tentang keterampilan motoric anak-anak dan cara mengajar yang benar terhadap keterampilan motorik (Famelia, Goodway, Bakhtiar, Mardela, 2016). Oleh sebab itu sangat diperlukan strategi tepat untuk meningkatkan kompetensi guru (Aboud, Proulx, Asrilla, 2016; Bakhtiar \& Famelia, 2018).

Salah satu wilayah yang mendapatkan pelatihan keterampilan gerak dasar anak usia dini adalah Kota Padang Panjang. Dari hasil program pelatihan yang telah pengabdi berikan terlihat bahwa guru-guru PAUD IGTK Padang Panjang memang sangat tertarik dengan kegiatan pelatihan semcam ini.Ternyata sebelumnya guru-guru ini belum tahu sama sekali tentang apa itu keterampilan gerak dasar sehingga mereka juga tidak memiliki rencana terstruktur dalam mengajarkan keterampilan gerak pada anak.

Pada kesempatan itu pengabdi menjelaskan bahwa mengajarkan gerak dasar pada siswa merupakan hal penting yang tidak bisa disepelekan. Karena keterampilan gerak dasar yang dimiliki oleh anak akan berkorelasi dengan perkembangan kemampuan kognitif anak, seperti menulis, membaca dan berhitung (Diamond, 2000, Ericsson, 2008, Piek, Dawson, Smith, Gasson, 2008, Raczek, 2010, Westendorp, Hartman, Houwen, Smith, Visscher, 2011, Singh, Uijtdewilligen, Twisk, Mechelen, Chinapaw, van der Fels, Ewierike, Hartman, Elferink-, Smith, Visscher; mArcin, Sara, Andrzej, 2017).

Mereka juga mengutarakan bahwa selama ini mereka tidak pernah tahu bahwa mengajarkan keterampilan gerak dasar pada anak juga sama pentingnya dengan mengajar kemampuan akademik. Mereka hanya membiarkan anak-anak memilih sendiri kegiatan apa yang diinginkan. Pengabdi menginginkan bahwa pelatihan yang telah diberikan pada guru PAUD Kota Padang Panjang ini tidak hanya sampai disitu saja, namun pengabdi juga ingin melakukan kegiatan pembinaan.Melalui kegiatan pembinaan ini diharapkan dapat mengontrol dan melakukan evaluasi terhadap pembelajaran gerak yang dilakukan oleh guru PAUD. Dengan begitu kita tetap bisa melakukan control terhadap proses pembelajaran yang diajarkan guru tersebut di sekolah supaya esensi dari kemampuan gerak dasar yang harus dicapai anak tetap terjaga.

\section{8 | Implementation Of Learning And Fundamental Measurement Of Early Syahrial Bakhtiar ${ }^{1}$, Zainul Johor $^{2}$, Oktarifaldi ${ }^{3}$, Lucy Pratama Putri ${ }^{4}$ http://jha.ppj.unp.ac.id}




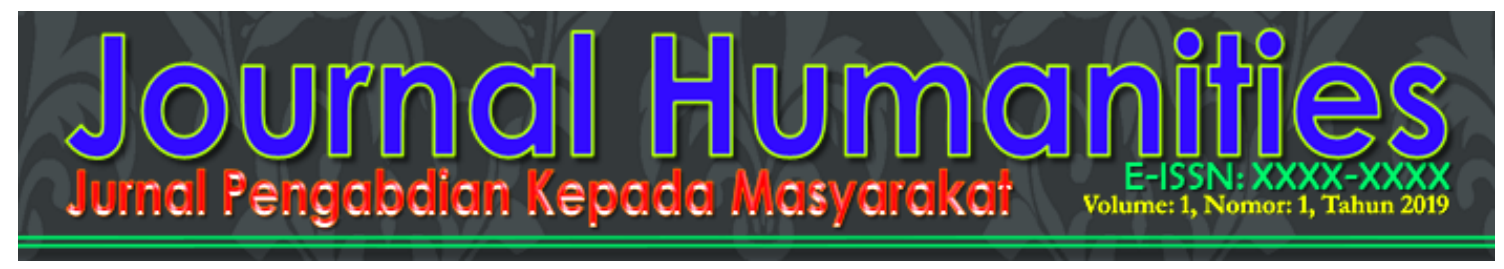

Berdasarkan kondisi serta situasi tersebut, untuk mengejar ketertinggalan bagi guru-guru PAUD yang telah berada di lapangan khususnya di sekolah tempat tugas masing-masing penulis ingin mengadakan suatu sosialisasi tentang pemahaman tentang materi gerak dasar serta cara mengimplementasikan dalam pengajaran kepada peserta didik di PAUD. Setelah memahami dan memiliki wawasan kegiatan selanjutnya pengabdi akan melanjutkan dengan bimbingan melalui pelatihan kepada guru PAUD dan TK di kota Padang Panjang. Fokus kegiatan adalah melatih guru untuk mengimplementasikan model pembelajaran gerak dasar kepada anak, dilanjutkan mengukur dan mengevaluasi keterampilan gerak dasar anak pada usia dini di kota Padang Panjang, serta implementasinya di sekolah-sekolah tempat tugas masingmasing guru.

\section{SOLISI DAN TARGET}

Salah satu program yang ditawarkan untuk menangani permasalahan mitra yaitu pembuatan panduan merancang pembelajaran, mengevaluasi dan cara pengukuran tes keterampulan gerak dasar anak secara sederhana agar bisa dipraktekkan kepada anak PAUD. Adapun bentuk yang dimaksud adalah mengetahui gerak lokomotor, non lokomotor serta control objek.

Selanjutnya memahami instrument tes keterampilan gerak dasar. Keinginan dari pengabdi adalah pembuatan buku yang harapannya adalah dapat dipubilkasikan dan digunakan bagi seluruh guru-guru tingkat TK/PAUD. Dengan pembelajaran ini ditambah materi tes keterampilan gerak dasar untuk anak usia dini, maka guru akan merasa lebih percaya diri dalam memberikan dan merangsang anak beraktivitas gerak secara benar khususnya gerak dasar yang baik.

Setelah mengaplikasikan semua rangkaian kegiatan tersebut barulah guru diberikan pengetahuan dan keterampilan dalam menyusun pembelajaran gerak dasar, yang selanjutnya dapat diimplementasikan dalam proses pembelajaran secara kontiniu. Beberapa yang harus diperhatikan dalam aktivitas pelatihan dan pembelajaran gerak dasar serta cara mengukur keterampilan gerak dasar anak diantaranya adalah :

1. Perhatian secara khusus terhadap keterampilan gerak dasar anak usia dini. Artinya kajian keilmuan yang mendalam tentang gerak dasar, belajar motorik dan pertumbuhan dan perkembangan.

2. Pembuatan buku sederhana yang nantinya bisa dijadikan guru dalam melakukan pengajaran gerak dasar dan cara pengukuran keterampilan gerak dasar anak khususnya anak TK/PAUD di kota Padang Panjang.

3. Adanya penilaian ahli mengenai produk akhir, seperti ahli gerak dasar, ahli pertumbuhan dan perkembangan, ahli ilmu gizi, belajar motorik. Tujuannya untuk menilai produk/buku yang dibuat agar lebih baik sebelum diterapkan guru terhadap anak.

4. Guru TK/PAUD dijadikan sebagi agen untuk mentransfer atau perantara informasi dari pengabdi kepada siswa PAUD.

\section{PELAKSANAAN KEGIATAN}

Sebelum kegiatan pengabdian dilaksanakan, tim pengabdian melakukan proses observasi terlebih dahulu kepada khalayak sasaran, guna menemukan masalah yang

\section{9 | Implementation Of Learning And Fundamental Measurement Of Early Syahrial Bakhtiar ${ }^{1}$, Zainul Johor $^{2}$, Oktarifaldi ${ }^{3}$, Lucy Pratama Putri ${ }^{4}$ http://jha.ppj.unp.ac.id}




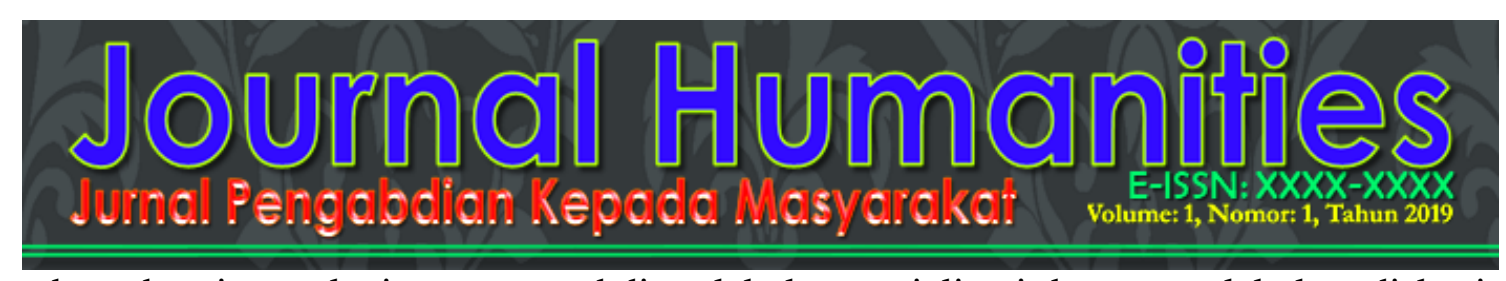

ada pada mitra, selanjutnya pengabdi melakukan sosialisasi dengan melakukan diskusi kebeberapa sekolah menemui guru dan kepala sekolah TK/PAUD di kota Padang Panjang untuk berkomunikasi dan menjelaskan tujuan dan pentingnya kegiatan pengabdian ini dilaksanakan. Kegiatan pengabdian ini dilakukan melalui:

\section{Pemberian Materi}

Pemberian materi dilakukan melalui beberapa metode kepada khalayak sasaran tentang pembelajaran gerak dasar serta instrument evaluasi gerak dasar dan penggunaannya. Diantra beberapa metode tersebut adalah : metode ceramah, demonstrasi, diskusi serta pemecahan masalah, selanjutnya pengabdi melakukan pendampingan dalam realisasi materi setelah kegiatan pelatihan dilakukan.

Materi yang diberikan memuat informasi tentang : (a) Wawasan pentingnya gerak dasar bagi anak usia dini, (b) Pengetahuan dan keterampilan gerak dasar bagi guru PAUD, (c) Instrument dan cara pengukuran gerak dasar bagi guru PAUD, (d) Keterampilan dalam merancang pembelajaran gerak dasar.

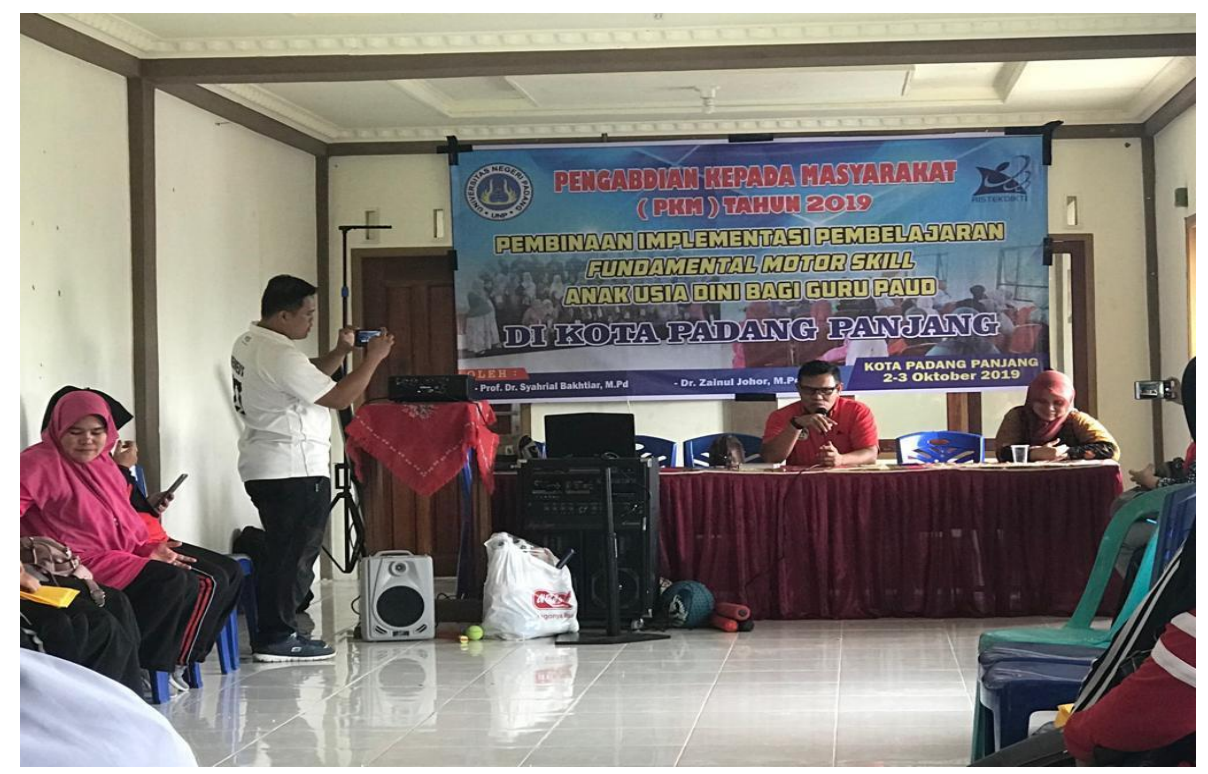

Gambar 1. Penyampaian materi

\section{Melakukan Diskusi dan Praktek Tentang Materi Gerak Dasar}

Diskusi ini dilakukan agar khalayak sasaran lebih memahami tentang gerak dasar. Khalayak sasaran sangat antusias dalam kegiatan diskusi ini karena mereka memiliki rasa ingin tahu yang besar tentang pentingnya gerak dasar bagi anak usia dini dan cara mengevaluasi awal kemampuan anak di TK dan PAUD. Khalaya sasaran juga diberikan kesempatan bertanya tentang materi yang disampaikan berkenaan dengan macam-macam gerak Objek Kontrol dan gerak Lokomotor. Selanjutnya untuk lebih paham dan menguasai secara ideal, pengebdi dan Tim melakukan demonstrasi dan mitra dipersilahkan untuk mempraktekkannya. 

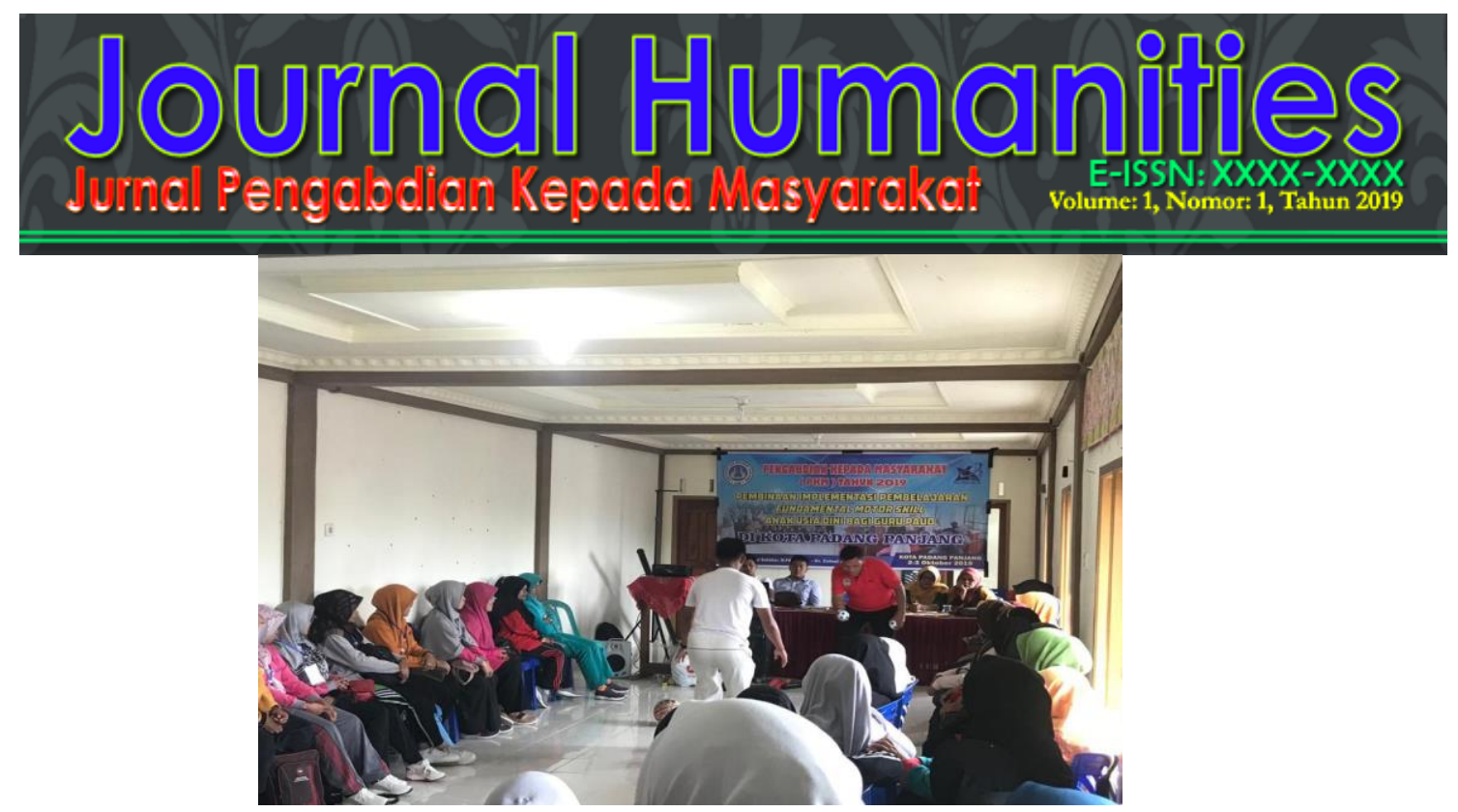

Gambar 2. Diskusi Tentang Materi Gerak Dasar Lokomotor dan Objek Kontrol

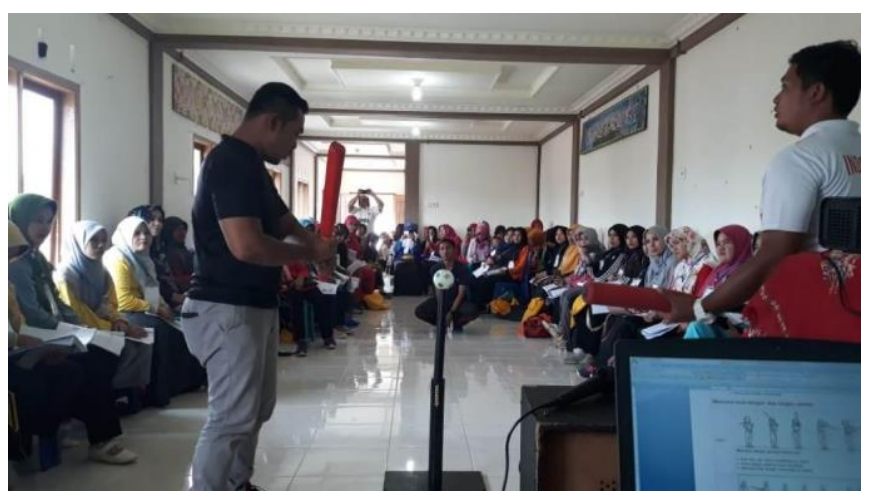

Gambar 3. Demonstrasi yang dilakukan TimPengabdi sebelum dipraktekkan Mitra

\section{Merancang Pembelajaran Gerak Dasar}

Setelah meteri disampaikan dan dilanjutkan dengan diskusi berkenaan dengan substansi, sesi selanjutnya dilakukan praktek merancang pembelajaran gerak dasar bagi masing-masing guru. Kegiatan diawali dengan pembagian kelompok serta mendiskusikan materi yang akan disampaikan agar transfer pengetahuan benar-benar diserap dan dikuasai dengan baik. tahap ini bertujuan untuk mendalami dan mengetahui secara ril proses pembelajaran gerak dasar dan proses evaluasi yang akan direalisasikan guru terhadap anak di TK dan PAUD.

Dalam perancangan model pembelajaran ini, Tim pengabdi selalu memberikan bimbingan jika terdapat kendala bagi guru dan kelompok mengajar. Dalam proses ini semua ide dari guru dapat ditampung dan Tim pengabdi hanya memberikan arahan agar produk yang dirancang dapat dijalankan secara efektif.

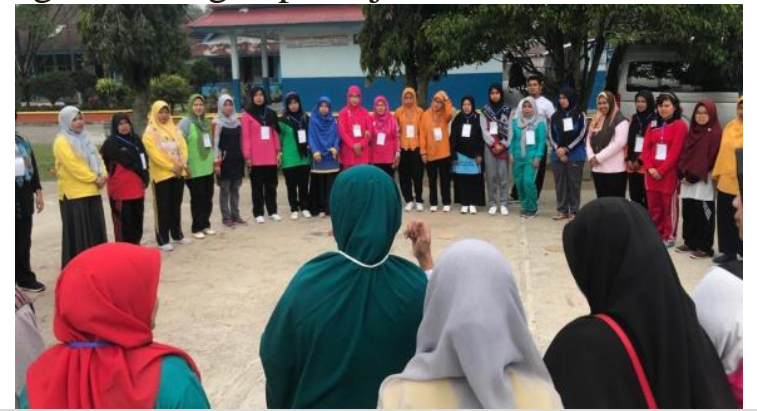

41 | Implementation Of Learning And Fundamental Measurement Of Early Syahrial Bakhtiar ${ }^{1}$, Zainul Johor ${ }^{2}$, Oktarifaldi $^{3}$, Lucy Pratama Putri ${ }^{4}$ http://jha.ppj.unp.ac.id 


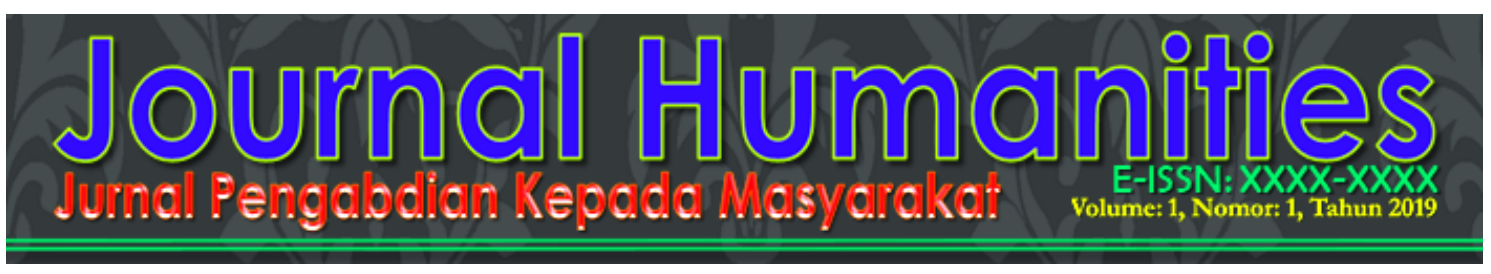

Gambar 4. Diskusi Sebelum Merancang Pembelajaran Gerak Dasar

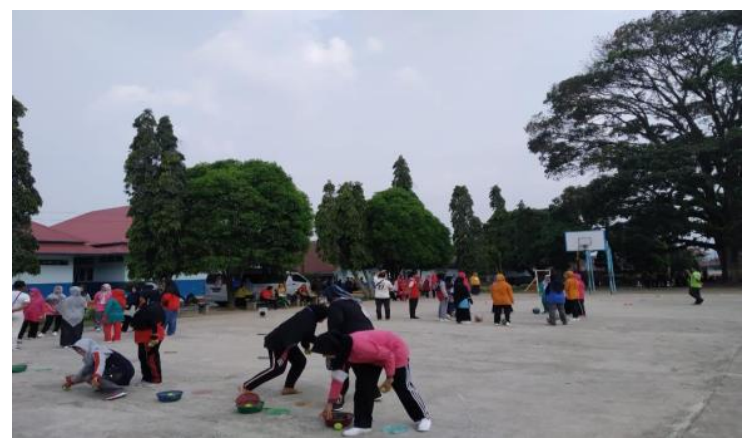

Gambar 5. Guru Mempraktekkan Model Pembelajaran Yang Telah Didiskusikan

Dalam merancang pembelajaran gerak dasar, guru dibimbing dalam memilih materi yang akan disampaikan. Materi yang disampaikan sesuia dengan pola gerak yang dianggap tidak terlalu rumit direalisasikan guru saat transisi dan saat praktek bagi anak. Selanjutnya dalam mempraktekkan item gerak lokomotor dan objek control pengabdi dan Tim memberikan arahan agar pembelajaran berjalan dengan efektif, baik dalam mempersiapkan kelas, media pembelajaran, memilih materi, membuka pembelajaran, menyampaikan materi inti dan penutupan pembelajaran (evaluasi).

Pengabdi dan Tim memberikan masukan kepada guru agar dapat memanfaatkan waktu sefektif mungkin.

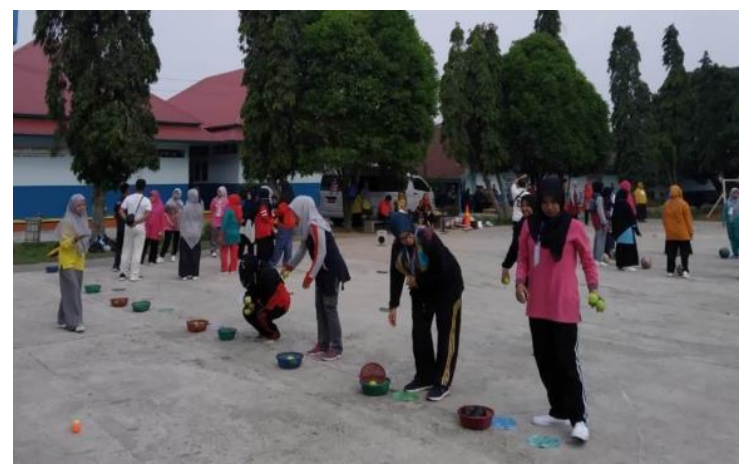

Gambar 6. Masing-Masing Kelompok Sedang Mempraktekkan Model Pembelajaran

\section{Melakukan Pendampingan Dalam Implementasi Pembelajaran Di Sekolah}

Pengabdian melakukan kegiatan pendampingan kepada Mitra (peserta Pelatihan) dengan mengunjungi sekolah mitra sebanyak 2 kali pertemuan. Kegiatan yang dilakukan adalah berupa diskusi, konsultasi serta evaluasi dalam proses pembelajaran gerak dasar di sekolah. Dalam proses pendampingan, pengabdi dan Tim memberikan solusi alternative dalam pembelajran jika terdapat aspek yang belum mendukung dalam pembelajaran gerak dasar.

Solusi yang berorientasi kepada tujuan pembelajaran gerak dasar selalu pengabdi sampaikan kepada mitra. Pengabdi dan Tim selalu menyediakan waktu jika ada pertanyaan tentang proses realisasi materi.

\section{2 | Implementation Of Learning And Fundamental Measurement Of Early}

Syahrial Bakhtiar ${ }^{1}$, Zainul Johor ${ }^{2}$, Oktarifaldi $^{3}$, Lucy Pratama Putri ${ }^{4}$

http://jha.ppj.unp.ac.id 

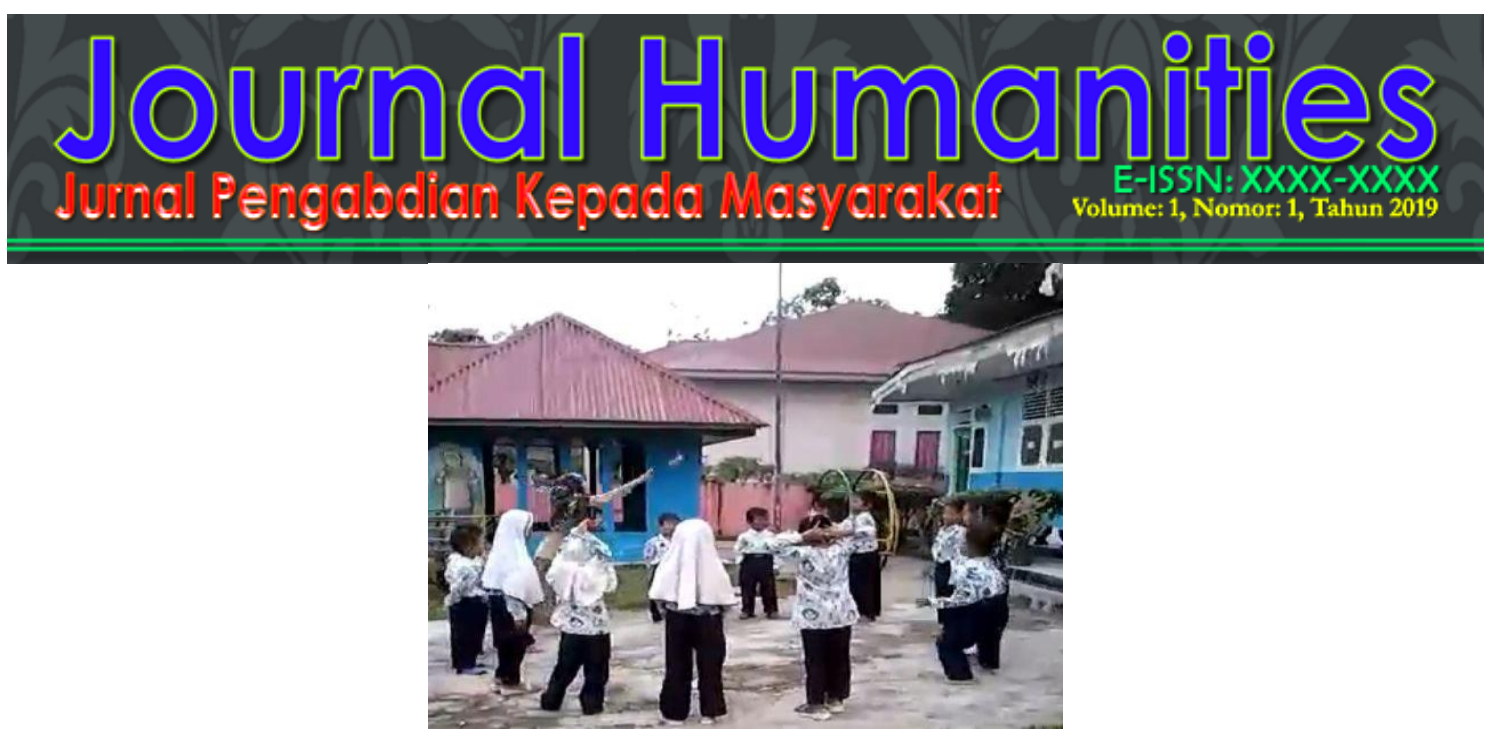

Gambar 7. Pendampingan Dalam Pembelajaran Gerak Objek Kontrol

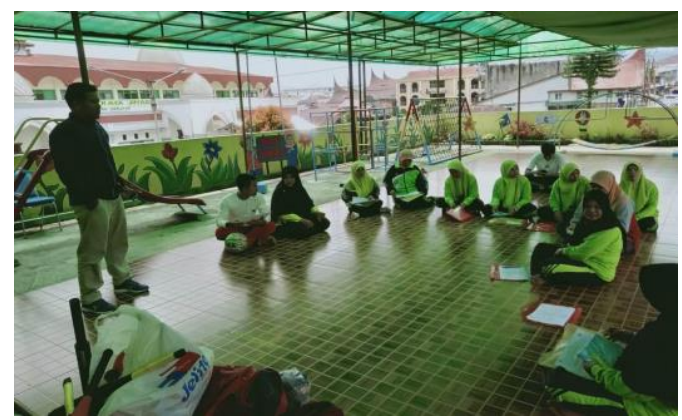

Gambar 8. Pendampingan Dalam Pembelajaran Gerak Lokomotor \& Objek Kontrol

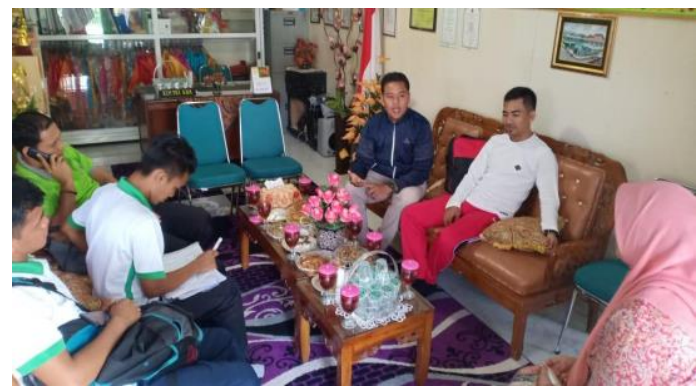

Gambar 9. Diskusi Dan Masukan Yang Tim Pengabdi Berikan Saat Pendampingan

\section{HASIL DAN PEMBAHASAN Hasil Pengabdian}

Pengabdian ini telah selesai dilaksanakan pada tanggal 2 samapai 3 Oktober 2019 di Aula SMA Negeri 1 Padang Panjang. Kegiatan ini dihadiri oleh Kepala Seksi bidang Pendidikan Anak Usia Dini Padang Panjang, Ketua IGTKI kecamatan Padang Panjang Barat dan ketua KKG TK Kota Padang Panjang dan guru-guru TK dan PAUD se kota Padang Panjang yang berjumlah 55 peserta.

Setelah mendapatkan wawasan, keterampilan dan pengalaman dalam pelaksanaan pembelajaran gerak dasar, kegiatan selanjutnya adalah monitoring dan pendampingan dalam mengimplementasikan materi. Hal tersebut pengabdi lakukan demi terealisasinya tujuan pengabdian kepada masyarakat secara efektif. Rangkaian

\section{3 | Implementation Of Learning And Fundamental Measurement Of Early}

Syahrial Bakhtiar ${ }^{1}$, Zainul Johor ${ }^{2}$, Oktarifaldi ${ }^{3}$, Lucy Pratama Putri ${ }^{4}$

http://jha.ppj.unp.ac.id 


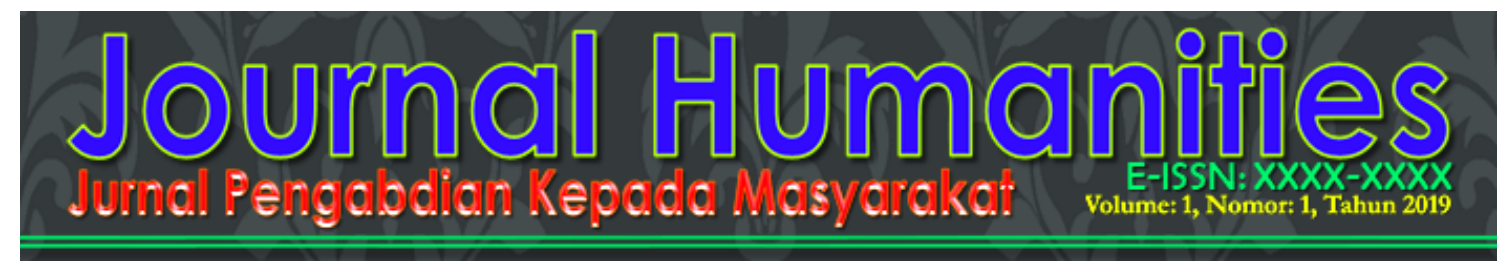

kegiatan selanjutnya adalah monitoring dan pendampingan yang pengabdi lakukan terhadap mitra.

Pendampingan I dalam implementasi pembelajaran oleh mitra (guru yang ikut pelatihan) dilaksanakan pada minggu berikutnya bulan Oktober 2019, pengabdi hadir mendampingi dan berdiskusi dengan guru tentang implementasi materi dan membentu memecahkan permasalahan yang ditemui saat penyampaian materi. Pendampingan II dilaksanakan minggu ke tiga bulan Oktober 2019, hal ini terfokus pada diskusi dan perbaikan metoda yang disampaikan oleg guru sesuai dengan kondisi sekolah dan sarana yang dimiliki.

Pengabdi dan mitra juga berdiskusi tentang hal-hal yang dianggap perlu untuk kelanjutan kegiatan dan membangun komunikasi dengan mitra secara kontiniu.

\section{Pembahasan}

Goodway dalam Sciencedaily (2010) menyatakan "banyak orang bahkan tenaga pendidik meyakini bahwa keterampilan gerak dasar berkembang secara alami, namun banyak studi yang kami lakukaan menunjukkan tidaklah demikian."Selama tahun-tahun sebelum memasuki sekolah dan masa sekolah dasar, kemampuan motorik (gerak) seorang anak mulai muncul dan berkembang.Perkembangan fisik dan pengalaman gerakan dari sejarah seorang anak memainkan peranan penting dalam mempengaruhi pemerolehan dalam pola gerak.

Jika kekurangan-kekurangan dalam perkembangan gerak dasar tidak dikenali dan diperbaiki, anak-anak akan mengalami masalah-masalah yang menetap dengan keterampilan gerak dikemudian hari. Mengingat pertumbuhan dan perkembangan otak terjadi pada usia 3-6 tahun, maka perlakuan untuk meningkatkan keterampilan kognitif anak perlu diterapkan dengan seksama. Penelitian sejumlah ahli (Chisholm et al., 1995; Chugani, 1996; Ramey \& Ramey, 1994; Singer, 1995) memperlihatkan bahwa ukuran, kompleksitas dan synapsis pada otak anak akan tumbuh seiring dengan peningkatan kuantitas dan kualitas pengalaman sensori saat beraktifitas fisik. Fakta ini menegaskan bahwa tidak hanya lama anak bermain yang harus ditingkatkan, namun kualitas dalam permainan juga harus diperhatikan.

Perkembangan gerak dasar menurut Ulrich (2000) sering diabaikan oleh para pendidik pada awal masa kanak-kanak. Goodway dalam Sciencedaily (2010) menyatakan "banyak orang bahkan tenaga pendidik meyakini bahwa keterampilan gerak dasar berkembang secara alami, namun banyak studi yang kami lakukaan menunjukkan tidaklah demikian." Selama tahun-tahun sebelum memasuki sekolah dan masa sekolah dasar, kemampuan motorik (gerak) seorang anak mulai muncul dan berkembang. Perkembangan fisik dan pengalaman gerakan dari sejarah seorang anak memainkan peranan penting dalam mempengaruhi pemerolehan dalam pola gerak

Dalam proses belajar gerak untuk anak usia sekolah dasar menurut Corbin (1980) adalah peletakan penguasaan berbagai gerak dasar. aktivitas tubuh yang membentuk gerak dasar menurut Laban dalam Rahantoknam (1992) dapat diklasifikasikan dalam tiga kategori yaitu :

a. Aktifitas lokomotor, aktivitas yang menyebabkan tubuh berpindah dari satu tempat ke tempat lain,

b. Aktifitas non lokomotor, aktivitas yang apat dilakukan tanpa harus berpindah tempat berpijak, atau tanpa maksud berpindah ke tempat lainnya,

\section{4 | Implementation Of Learning And Fundamental Measurement Of Early}

Syahrial Bakhtiar ${ }^{1}$, Zainul Johor ${ }^{2}$, Oktarifaldi ${ }^{3}$, Lucy Pratama Putri ${ }^{4}$

http://jha.ppj.unp.ac.id 


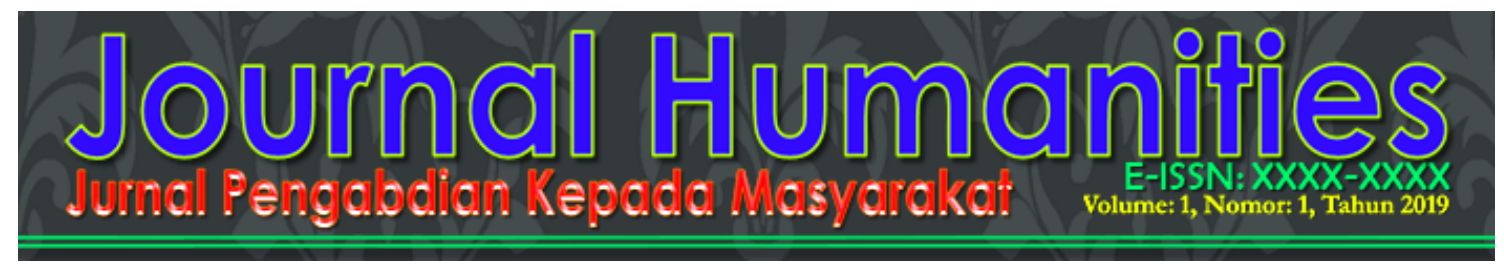

c. Aktivitas manipulasi, aktivitas yang digunakan untuk menipulasi atau menghindari alat.

TKGD merupakan tes yang digunakan untuk mengevaluasi kemampuan gerak dasar individu, khususnya anak usia 3 hingga 10 tahun.Tujuan dari TKGD, yaitu: Mengidentifikasi keterlambatan perkembangan keterampilan gerak dasar pada anak.

a. Merencanakan program instruksional untuk pengembangan keterampilan gerak dasar.

b. Menilai kemajuan perkembangan keterampilan gerak dasar individu. c.

Mengevaluasi

keberhasilan program keterampilan gerak dasar.

c. Sebagai instrument pengukuran dalam penelitian yang berhubungan dengan perkembangan gerak dasar.

Material dan perlengkapan yang diperlukan untuk melaksanakan TKGD terdiri atas lembaran manual bagi penguji, lembaran untuk mencatat hasil tes dan beberapa alat adalah: (1) Bola karet dengan diameter $20-25 \mathrm{~cm}$, (2) Bola plastik ringan dengan diameter $10 \mathrm{~cm}$, (3) Bola plastik/busa diameter $7-8 \mathrm{~cm}$, (4) Bola basket, (5) Bola tenis, (6) Bola kaki, (7) Beanbag bujur sangkar ukuran $10-12 \mathrm{~cm}$, (8) Tongkat pemukul berbahan plastik, (9) Kerucut pendek (half cones), (10) Tiang tempat bola (batting tee), (11) Penanda lantai (kapur, atau lakban, atau polyspots). Dalam pelaksanaan tes TKGD setiap anak memerlukan waktu sekitar 15-20 menit. Selain itu diperlukan waktu tambahan untuk persiapan dan pembersihan alat sekitar 10 menit.

Agar waktu pelaksanaan tes berjalan optimal, sediakan alat dalam jumlah yang cukup, misalnya bola dan pemukul, lalu kondisikan anak beralih dari satu tes ke tes lain dengan cepat. Biasanya hanya diperlukan satu sesi saja untuk melaksanakan seluruh tes tapi untuk membiasakan anak dengan lingkungan maka berikanlah beberapa sesi agar evaluasi menjadi lebih optimal.

\section{KESIMPULAN}

Berdasarkan kegiatan Pengabdian Kepada Masyarakat yang sudah dilaksanakan di kota Padang Panjang, dapat disimpulkan sebagai berikut:

1. Pelaksanaan Kegiatan Pengabdian Kepada Masyarakat ini telah berhasil dilaksanakan dengan baik tanpa mengalami kendala yang berarti.

2. Kegiatan Kegiatan Pengabdian Kepada Masyarakat ini memberikan edukasi bermanfaat kepada masyarakat (guru, orang tua, peserta didik) kota Padang Panjang. Mengenai defenisi, pemahaman dan wawasan mengenai pembelajaran keterampilan gerak dasar anak usia dini bagi guru PAUD di kota Padang Panjang.

3. Kegiatan Pengabdian Kepada Masyarakat ini memberikan gambaran dan fakta yang terjadi secara umum mengenai kemampuan anak serta pentingnya pembelajaran gerak dasar anak usia dini.

Kegiatan ini secara keseluruhan telah memberikan pengetahuan dan pengalaman bagi guru dalam mendemonstrasikan serta merancang pembelajaran gerak dasar anak usia dini kepada mitra (guru-guru PAUD). Selanjutnya guru PAUD di kota Padang Panjang. telah memiliki pengalaman dan keterampilan dalam mengevaluasi gerak dasar anak.

\section{DAFTAR PUSTAKA}

45 | Implementation Of Learning And Fundamental Measurement Of Early Syahrial Bakhtiar $^{1}$, Zainul Johor ${ }^{2}$, Oktarifaldi ${ }^{3}$, Lucy Pratama Putri ${ }^{4}$ http://jha.ppj.unp.ac.id 


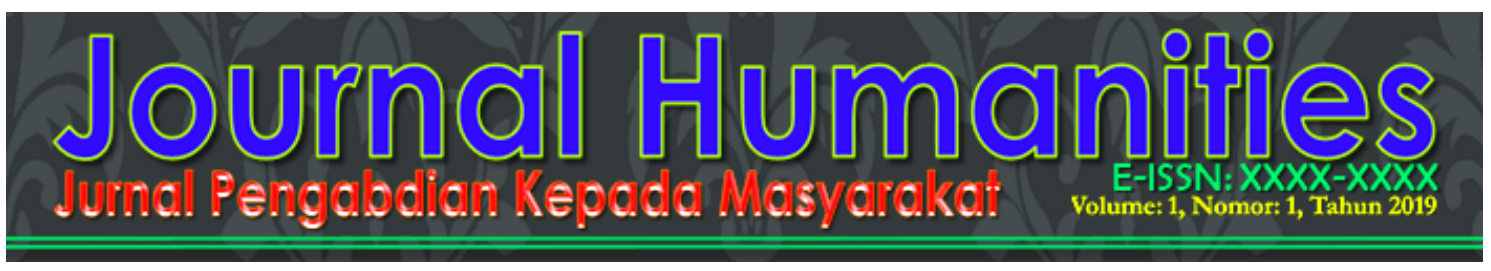

UNDANG-UNDANG REPUBLIK INDONESIA NOMOR 20 TAHUN 2003 TENTANG

NASIONAL. SISTEM

PENDIDIKAN content/uploads/2016/08/UU_no_20_th_2003.pdf.

Dahar, Ratna. 2006. Teori-Teori Belajar \& Pembelajaran. Jakarta : Erlangga.

Li, L. (2009) Children Gross Motor Development from Ages 3 to 10 in Shandong. Journal of Shandong Institute of Physical Education and Sports, 25(4), 47-50.

Clark JE, Metcalfe JS. (2002). The mountain of motor development.In: Clark JE, Humprehy JH, editors. Motor development:research and reviews. Vol. 2. Reston (VA): National As-sociation of Sport \&Physical EducationUlrich, D.A. (2000). Test of gross motor development (2nd ed.). Austin, TX: Pro-Ed

Martin Vaculik, Petr Smutny \& Jakub Prochazka. 2017. Fundamental motor skills of Czech children at the end of the preschool period. Acta Gymnica 2017, 47(4):193-200 | DOI: 10.5507/ag.2017.0247.

R Famelia, JD Goodway, S Bakhtiar, R Mardela. 2016. Investigating The Motor Competence And Physical Activity Of Indonesian, Muslim Preschoolers From Urban And Rural Areas. JOURNAL OF SPORT \& EXERCISE PSYCHOLOGY 38, S33-S33.

S Bakhtiar, R Famelia. 2018. Institute Role of Teachers' Education in Improving the Standard of Development Achievement Rate and Standard of Teacher and Education Personnels of Early Childhood Education. DOI: 10.2991/icece-17.2018.20. Conference: International Conference of Early Childhood Education (ICECE 2017).

Marcin Korbecki, Andrzej Rokita \& Sara Wawrzyniak. 2017. Fundamental movement skills of six- to seven-year-old children in the first grade of elementary school: A pilot study. DOI: 10.29359/BJHPA.09.4.0

Sciencedaily. 2010. 86 percent of disadvantaged preschoolers lack basic motor skills. Source: Ohio State University. https://www.sciencedaily.com/releases/2010/04/100426131608.htm

Jacqueline D. Goodway, Leah E. Robinson, and Heather Crowe. ender Differences in Fundamental Motor Skill Development in Disadvantaged Preschoolers From Two Geographical Regions. Research Quarterly for Exercise and Sport, March 2010, Vol.81, No. 1.

Corbin, Charles B. (Ed.). (1980). A Texbook of Motor Development. 2nd Edition. Dubuque, Iowa: Wm C. Brown Company Publishers.

46 | Implementation Of Learning And Fundamental Measurement Of Early Syahrial Bakhtiar ${ }^{1}$, Zainul Johor ${ }^{2}$, Oktarifaldi $^{3}$, Lucy Pratama Putri ${ }^{4}$ http://jha.ppj.unp.ac.id 


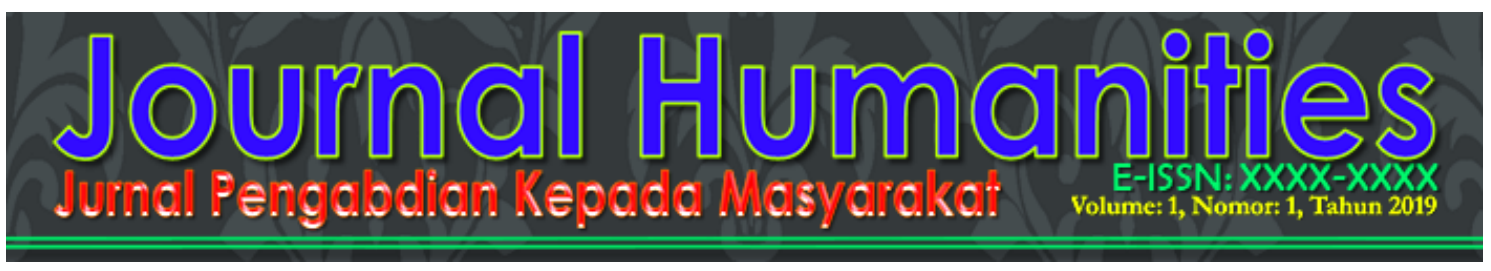

Ramey, C. T. \& Ramey, S. L. (1994). Which children benefit the most from early intervention? Pediatrics, 94, 1064-1066.

Rahantoknam, B. Edward (1992). Belajar Motorik: Teori dan Aplikasinya Dalam Pendidikan Jasmani. Jakarta : Proyek Pengembangan Lembaga Pendidikan Tenaga Kependidikan. 